\title{
Ordering of taboo adjectives
}

\author{
TIMOTHY B. JAY \\ North Adams State College, North Adams, Massachusetts 01247
}

and

JOSEPH H. DANKS

Kent State University, Kent, Ohio 44242

\begin{abstract}
The productivity of an adjective ordering rule based on definiteness of denotation was assessed by comparing preferred orderings of taboo and nontaboo adjectives in noun phrases. Taboo adjectives were just as stable as nontaboo adjectives in their preferred position in adjective ordering. When given instructions to interpret the taboo adjectives denotatively, subjects preferred them closer to the noun than when the adjectives were interpreted connotatively, the latter being the typical interpretation given no instructions. Results support the notion that a functional determinant of adjective ordering is the definiteness of denotation.
\end{abstract}

English as well as other languages has a preferred order of adjectives relative to the modified noun. For example, the small yellow butterfly is preferred to the yellow small butterfly. A common finding has been that semantic properties of the adjectives, such as definiteness and absoluteness of denotation (Martin, 1969) and instrinsicalness (Danks \& Glucksberg, 1971), are highly correlated with adjective ordering. The data supporting this explanation are solely correlations between preferred adjective order and subjective ratings of the semantic properties in question (Martin, 1969). There has been no experimental demonstration that changes in the semantic properties of words produce changes in preferred adjective ordering.

Recent work on the mental dictionary has tended to emphasize the denotative side of lexical meaning in contrast to the connotative (see Glucksberg \& Danks, 1975; Miller \& McNeill, 1969, for overviews). Denotative meaning is the mental representation of the set of objects, characteristics, or events that a word is used to refer to. In contrast, the connotative meaning is the affective or emotional representation commonly associated with the denotative meaning. It is difficult to separate these two aspects of a word's meaning for study. When one hears or sees a word, the denotative meaning immediately comes to mind (Warren, 1972) and one can do little to inhibit the connotations associated with it.

There is one class of words that is unique in that the

The research reported here is based on a master's thesis presented to Kent State University by the first author. The research was supported in part by Grant MH 21230 from NIMH to the second author. Requests for reprints should be sent to T. B. Jay, Department of Psychology, North Adams State College, North Adams, Massachusetts 01247. connotative meaning is dominant over the denotative meaning and the two aspects of meaning can be separated. This class consists of taboo words, commonly known as "dirty words," or simply "an expression which is inhibited" (Leach, 1966, p. 24). Taboo expressions typically are interpreted in the connotative sense (as we shall demonstrate in these experiments). Connotation is generally linked to emotional expression, not to denotating a specific property of the person in question. The idea of using taboo words denotatively is not unusual. D. H. Lawrence (1959) did so in Lady Chatterley's Lover and Lenny Bruce was arrested for doing the same (Bruce, 1963).

How are connotation and denotation related to definiteness? If taboo adjectives are interpreted connotatively, they can be applied to most nouns to express a generalized negative emotion. If they are interpreted denotatively, most taboo adjectives can be applied only to animate beings, and often only to humans. "Bill is shitty" and "Racism is shitty" express the speaker's dislike for Bill and racism. If Bill is a 1-year-old with diarrhea, then the description may be denotatively accurate (as well as expressing his parents' frustration). However, because racism is abstract, a denotative interpretation of shitty can be at best metaphorical. Thus, it is reasonable to assume that a denotative interpretation is more definite in meaning than is a connotative interpretation because of the reduced range of applicability.

Assuming that taboo words are typically used connotatively and that connotation is more indefinite, then with no instructions about interpretation, taboo adjectives would be preferred farther from the noun in a noun phrase than most nontaboo adjectives according to an adjective ordering rule based on definiteness. But if subjects were given a denotative set, then the preferred placement of the taboo adjective would be relatively 
closer to the noun. For example, if subjects chose which of two phrases sounds more natural (preferred order), a phrase like the shitty rough person would be preferred to the phrase the rough shitty person. In contrast, if taboo adjectives were interpeted denotatively, then the reverse order would be preferred. The adjective shitty typically connotes generalized dislike which is less definite in meaning than rough. But denotatively, shitty can apply only to animate beings, whereas rough can apply to inanimate objects as well as abstract ideas. In the former case, rough is more definite in meaning; in the latter case shitty is. This difference in meaning would be reflected in the different preferred orders of the adjectives.

\section{EXPERIMENT 1}

The primary purpose of this experiment was to assess the stability of preferred order to taboo adjectives. Some adjectives are consistently preferred closer to a noun than others. This effect can be measured by the proportion of times an adjective is preferred closer to the noun when paired with other adjectives (Martin, 1969). Do taboo adjectives exhibit the same consistency and range of preference proportions? Pairing taboo adjectives either with a nontaboo adjective or with another taboo adjective before either of two nouns, person or rock, established these preferred order proportions.

\section{Method \\ Materials. The 28 obscenities most frequently produced by college students were selected from Foote and Woodward's (1972) list. These terms along with 32 nontaboo words were rated for frequency of usage and degree of tabooness by a separate sample of 52 undergraduates at Kent State University (for details see Jay, Note 1). Based on these ratings, 10 taboo words that could be converted to adjectives were selected to cover the range of both dimensions. The words selected and their ratings on frequency and tabooness are listed in Table 1. For these 10 words the correlation between the two ratings was -.43 .}

Ten nontaboo adjectives were selected from Martin (1969) and are listed in Table 1, with one exception noted below. Nontaboo adjectives were selected that did not create an apparently anomalous phrase when combined with either noun, person or rock. The nontaboo adjectives were not rated on either tabooness or frequency, but were selected to cover a wide range of proportion preference close to the noun according to Martin (1969).

Four lists were constructed using the 20 adjectives. Each adjective was paired with every other adjective in a noun phrase modifying either person or rock. All possible combinations of taboo-taboo, taboo-nontaboo, and nontaboo-nontaboo were included except that round was accidentally not paired with any taboo adjective. The 180 phrases were randomly ordered for Lists $\mathbf{A}$ and $B$ and arranged in pairs of phrases: "the + $A d j_{i}+A d j_{j}+$ Noun" and "the $+A d_{j}+A_{j} j_{i}+$ Noun." Each trial consisted of hearing a pair of phrases in which the only difference was the reversal of the adjectives preceding the noun. To control for order effects, the 180 pairs of phrases were rerandomized for Lists $C$ and $D$ and the order within each pair of phrases was reversed. Lists $A$ and $C$ used the noun person and Lists $B$ and $D$ the noun rock.

In recording each list, the speaker stressed each adjective equally with a slight juncture between the adjectives and a falling intonation on the noun. There was a 1-sec pause between phrases on each trial and $5 \mathrm{sec}$ between trials.

Procedure. Subjects were tested in groups for each of the four list conditions. Subjects were informed that the study involved judgment of obscene phrases and that they would remain anonymous. They then were instructed that they would hear pairs of phrases (an example was provided) and that they were to indicate which of the two word orders sounded more natural. Subjects indicated on answer sheets whether the first or second of the pair of phrases was preferred.

Subjects. The subjects were 120 native English speakers (15 males and 15 females for each list) enrolled in an introductory psychology course at Kent State University. Each received points convertible to course credit for participation. Data from five additional subjects were discarded for obvious response biases, for example, choosing only the first alternative on all trials.

\section{Results and Discussion}

The basic datum was the proportion of times that a given adjective was preferred closer to the noun when paired with a taboo or a nontaboo adjective. The means across nouns, lists, and subjects are shown in Table 1. For example, shitty was preferred closer to the noun (i.e., in second position) $40.0 \%$ when paired with another taboo word and $45.5 \%$ when paired with a nontaboo adjective. The data from round were omitted from all analyses. Analyses of variance were computed on these data with noun (person or rock), list (A, B, C, and $D$ ), and sex as between-subject variables and pairing (taboo or nontaboo) and individual words as withinsubject variables. Separate analyses were computed for the taboo and nontaboo adjectives, since they were based on the same preferences, but combined differently across adjectives.

Taboo adjectives. The primary purpose of this experiment was to determine whether taboo adjectives would be ordered consistently or whether the placement would be relatively arbitrary with little agreement among subjects. There was a reliable preference of placement of taboo adjectives as demonstrated by the significant main effect of words $[F(9,1008)=114.79$, $\mathrm{p}<.001]$. There were, in addition, three interactions involving words that might have compromised this main effect: Noun by Words $[\mathrm{F}(9,1008)=3.47, \mathrm{p}<.001]$; Sex by Words $[\mathrm{F}(9,1008)=3.44, \mathrm{p}<.001]$; and Pairing by Words $[F(9,1008)=6.93, p<.001]$. However, all three interactions did not affect the basic ordering of taboo adjectives in terms of the proportion of times they were preferred closer to the noun. For example, comparison of the Pairing by Words interaction in Table 1 shows that the relative order of the taboo adjectives was substantially unchanged by a pairing with either taboo or nontaboo adjectives $(r=.93)$.

Two other interactions were significant: List by Sex $[F(1,112)=3.91, p<.05]$ and List by Sex by Pairing $[F(1,112)=4.45, p<.05]$. Since there were no obvious regularities in these interactions and since they did not affect the basic findings, we will not consider them further.

There was a substantial tendency for the preferred 
Table 1

Mean Frequency and Tabooness Ratings and Proportion of Times Adjective Was Preferred Closer to a Noun as a Function of Pairing

\begin{tabular}{|c|c|c|c|c|c|}
\hline & \multicolumn{2}{|c|}{ Ratings } & \multicolumn{3}{|c|}{ Proportion Preference } \\
\hline & $\begin{array}{c}\text { Fre- } \\
\text { quency }\end{array}$ & $\begin{array}{c}\text { Taboo- } \\
\text { ness }\end{array}$ & Taboo & $\begin{array}{l}\text { Non- } \\
\text { taboo }\end{array}$ & Mean \\
\hline \multicolumn{6}{|l|}{ Taboo } \\
\hline $\begin{array}{l}\text { Damn } \\
\text { Goddamn } \\
\text { Fucking } \\
\text { Shitty } \\
\text { Pissy } \\
\text { Motherfucking } \\
\text { Bitchy } \\
\text { Sucking } \\
\text { Blowing } \\
\text { Cocksucking }\end{array}$ & $\begin{array}{l}8.38 \\
7.87 \\
7.13 \\
8.52 \\
5.98 \\
5.52 \\
7.21 \\
5.44 \\
4.88 \\
3.38\end{array}$ & $\begin{array}{l}3.73 \\
5.44 \\
7.98 \\
5.38 \\
5.23 \\
8.56 \\
5.31 \\
5.77 \\
4.13 \\
8.04\end{array}$ & $\begin{array}{l}.210 \\
.235 \\
.425 \\
.400 \\
.529 \\
.565 \\
.493 \\
.534 \\
.542 \\
.562\end{array}$ & $\begin{array}{l}.195 \\
.258 \\
.349 \\
.455 \\
.517 \\
.487 \\
.559 \\
.542 \\
.578 \\
.564\end{array}$ & $\begin{array}{l}.202 \\
.246 \\
.387 \\
.427 \\
.523 \\
.525 \\
.526 \\
.538 \\
.560 \\
.563\end{array}$ \\
\hline \multicolumn{6}{|l|}{ Nontaboo } \\
\hline $\begin{array}{l}\text { Large } \\
\text { Soft } \\
\text { Thin } \\
\text { Hot } \\
\text { Rough } \\
\text { Dry } \\
\text { Weak } \\
\text { Fragile } \\
\text { Red }\end{array}$ & & & $\begin{array}{l}.321 \\
.366 \\
.413 \\
.413 \\
.461 \\
.447 \\
.459 \\
.488 \\
.517\end{array}$ & $\begin{array}{l}.165 \\
.292 \\
.378 \\
.427 \\
.494 \\
.508 \\
.498 \\
.606 \\
.631\end{array}$ & $\begin{array}{l}.243 \\
.329 \\
.396 \\
.420 \\
.478 \\
.478 \\
.479 \\
.547 \\
.601\end{array}$ \\
\hline
\end{tabular}

Note $-1=$ low frequency and tabooness, $9=$ high frequency and tabooness.

order proportions to correlate with rated frequency $(\mathrm{r}=-.76)$. This correlation is a bit higher than Martin (1969) found between preferred order proportions and objective frequency of occurrence for two larger samples of adjectives ( $\mathrm{r}=-.51$ and -.62$)$. The correlation between tabooness ratings and preferred order proportions was small $(\mathrm{r}=.33)$. There was some tendency for the more taboo adjectives to be preferred closer to the noun.

In summary, taboo adjectives do vary consistently in their preferred ordering before nouns just as nontaboo adjectives do; furthermore, that ordering is stable across two different nouns and for both male and female judges.

\section{EXPERIMENT 2}

This experiment was designed to assess more directly the productivity of an adjective ordering rule based on definiteness of denotation. Assuming that variation in connotative-denotative interpretation reflects definiteness, it was predicted that a taboo adjective interpreted denotatively should be preferred closer to the noun person as compared to when it is interpreted connotatively.

\section{Method}

Materials. Five taboo and five nontaboo adjectives were chosen from Experiment 1. The taboo adjectives (damned, fucking, shitty, pissy, and cocksucking) ranged in proportion of times preferred closer to the noun from .202 to .563 . The tabooness and frequency ratings, obtained previously, were used to provide a range of words on both tabooness and frequency dimensions. The nontaboo adjectives (soft, thin, weak, large, and fragile) ranged in proportion of times preferred closer to the noun from .243 to .547 .

Each taboo adjective was used with each nontaboo adjective in a noun phrase with person, yielding 25 pairs of phrases. Adjectives of the same type were not paired. The pairs were randomized with the restriction that no adjective was heard on two consecutive trials. A second list was constructed by rerandomizing the first list and inverting within-trial order. The lists were tape recorded with the same intonation pattern and time intervals as in Experiment 1. Five warm-up trials preceded the 25 experimental trials.

Subjects. A total of $\mathbf{4 2}$ male and $\mathbf{4 2}$ female students (equally represented in three instructional conditions) enrolled in an introductory psychology course at Kent State University participated. Subjects were native English speakers and were given points convertible to course credit for participation.

Procedure. Subjects, tested in groups, heard the same introductory (similar to Experiment 1 ) and general instructions about comparing pairs of phrases to determine which sounded more natural. Then they were instructed appropriately for their assigned group (control, connotative, or denotative).

The connotative group was told that the experiment was designed "to look at the way we use obscene expressions, especially in their connotative meanings." Next, definitions of both connotation and denotation were provided, followed by an example of how obscene words were used connotatively to express emotions. All 10 taboo and nontaboo adjectives were listed. It was stressed that subjects were to "think of the list of obscene words in their connotative meanings only." Following an example of nontaboo adjective ordering, a second example asked subjects to judge which of two orders with taboo adjectives sounded better.

The denotative group was instructed that the experiment was designed "to look at the denotative capabilities of obscene words." Definitions of both denotation and connotation were given with an example. Subjects were also given a brief lecture on the history of taboo words. The experiment was described as an attempt to turn the clock back to the time when currently obscene words were used in everyday speech. Subjects were next provided with brief denotative definitions of the 10 adjectives from Partridge (1961) for taboo and Webster's Seventh New Collegiate Dictionary (1967) for nontaboo. An example trial was provided. Finally, subjects were reminded to consider only the denotative meanings of the words and judge which order sounded better to them.

A third group of subjects was given no instructions relative to connotation and denotation. The control instructions began with a general introduction followed by an example of adjective ordering. The experiment was described as involving judgment about noun phrases in which subjects were to choose which order of adjectives sounded better.

\section{Results}

The basic datum was the number of times an adjective was preferred closer to the noun out of five possible comparisons. The variables in the analyses of variance (one analysis for taboo adjectives and another for nontaboo adjectives) were instructions, list, and sex, all of which were between-subject variables. Words was considered a random variable (within-subject) along with subjects. A quasi $F\left(F^{\prime}\right)$ was calculated to test for reliability across both words and subjects simultaneously (Clark, 1973; Winer, 1971).

The effect of instructions was significant both for taboo adjectives $\left[\mathrm{F}^{\prime}(2,45)=5.80, \mathrm{p}<.01\right]$ and for nontaboo adjectives $\left[\mathrm{F}^{\prime}(2,66)=6.73, \mathrm{p}<.01\right]$. As 
Table 2

Proportion of Times Each Taboo Adjective Was Preferred Closer to a Noun as a Function of Instructional Condition

\begin{tabular}{lccc}
\hline \multirow{2}{*}{$\begin{array}{c}\text { Taboo } \\
\text { Adjective }\end{array}$} & \multicolumn{3}{c}{ Instructional Condition } \\
\cline { 2 - 4 } Damned & .450 & .171 & .200 \\
Fucking & .614 & .300 & .372 \\
Pissy & .650 & .492 & .508 \\
Shitty & .592 & .472 & .550 \\
Cocksucking & .670 & .564 & .614 \\
Mean & .595 & .400 & .449 \\
\hline
\end{tabular}

shown by the means in Table 2 , the taboo adjectives were preferred closer to the noun under denotative instructions than under connotative instructions. As expected, the control group interpreted the taboo adjectives in a connotative manner, at least with respect to adjective ordering, preferring the taboo adjective further from the noun. These individual comparisons were confirmed with Newman-Keuls analysis. The means for the nontaboo adjectives were necessarily the complement of the taboo means because a response indicated that either a taboo or a nontaboo adjective was preferred closer to the noun. None of the other effects was significant.

\section{GENERAL DISCUSSION}

That variation in semantic interpretation produces variation in preferred adjective ordering was demonstrated in Experiment 2. The denotative shift held even though the base proportion preference (Table 1) ranged from adjectives preferred close to the noun (cocksucking, .563) to adjectives infrequently preferred close to the noun (damn, .202). The effect was present in all five taboo words (see Table 2) and was reliable by the conservative quasi-F test. When in first position, two of the taboo adjectives (damned and fucking) can be interpreted ambiguously as modifying either the noun or the second adjective. For example, in That was a damned good béarnaise sauce, damned probably would be interpreted as an adverb intensifying the meaning of the adjective good. That is, a damned good béarnaise sauce is a very good béarnaise sauce. The availability of this alternative interpretation may account for the fact that the proportions in the connotation and control groups were low for damned and fucking, producing an enhanced denotative shift for these two words. But this could not be the whole explanation because the denotative-connotative effect was obtained for all five taboo adjectives, including pissy, shitty, and cocksucking, which are difficult to interpret as adverbs. When given no instructions as to how to interpret the taboo adjectives, subjects apparently interpreted them in a connotative sense, since there was no difference in the adjective ordering preferences under connotative and control instructions. This finding confirmed our intuition that taboo words are typically interpreted connotatively in everyday speech.

The results support the notion that a primary functional determinant in adjective ordering preferences is definiteness of denotation or some semantic construct highly correlated with definiteness. Adjective ordering preferences are not static, fixed properties of the adjectives but are susceptible to variation as a function of semantic interpretation (Experiment 2) as well as the pragmatic context of the utterance (Danks \& Schwenk, 1972). Manipulating semantic interpretation experimentally provides a firmer basis for asserting the functional productivity of semantically governed adjective ordering than do correlations between semantic properties and adjective ordering. It is possible that children learn the adult adjective order in an unprincipled, rote fashion. But if that is the case, by the time they become adults, they have internalized a semantic basis that can be used productively.

Precisely what the underlying semantic basis for normal adjective ordering is has not been established. It may be definiteness of denotation, as we assumed here, range of applicability, absoluteness, intrinsicalness, or some other dimension. Whatever it is, it was effectively manipulated by denotativeconnotative instructions, and so must be related to what subjects understand by those terms.

\section{REFERENCE NOTE}

1. Jay, T. B. The semantic function of taboo words: Connotation and denotation. Unpublished Master's Thesis, Kent State University, 1974.

\section{REFERENCES}

BRUCE, L. How to talk dirty and influence people. Chicago: HMH, 1963.

Clark, H. H. The language-as-fixed-effect fallacy: A critique of language statistics in psychological research. Journal of Verbal Learning and Verbal Behavior, 1973, 12, 335-359.

Danks, J. H., \& Glucksberg, S. Psychological scaling of adjective orders. Journal of Verbal Learning and Verbal Behavior, 1971, 10, 63-67.

Danks, J. H., \& Schwenk, M. A. Prenominal adjective order and communication context. Journal of Verbal Learning and Verbal Behavior, 1972, 11, 183-187.

Danks, J. H., \& Schwenk, M. A. Comprehension of prenominal adjective orders. Memory \& Cognition, 1974, 2, 34-38.

Foote, R., \& WoODWARD, J. Obscenity is in the mouth of the beholder? A linguistic-psychological study into dirty language. Psychonomic Society, St. Louis 1972.

GluCKSBERG, S., \& DANKs, J. H. Experimental psycholinguistics. Hillsdale, N.J: Lawrence Erlbaum, 1975.

LAwrence, D. H. Lady Chatterley's lover. New York: The New American Library, 1959.

LEACH, E. Anthropological aspects of language: Animal categories and verbal abuse. In E. H. Lenneberg (Ed.), New directions in the study of language. Cambridge: MIT Press, 1966.

Martin, J. E. Semantic determinants of preferred adjective order. Journal of Verbal Learning and Verbal Behavior, 1969, 8, 697-704.

Miller, G. A., \& McNeill, D. Psycholinguistics. In G. Lindzey \& E. Aronson (Eds.), Handbook of social psychology (Vol. 3). Reading, Mass: Addison-Wesley, 1969.

PARTRIDGE, E. A dictionary of slang and unconventional English. New York: Macmillan, 1961.

W ARREN, R. E. Stimulus encoding and memory. Journal of Experimental Psychology, 1972, 94, 90-100.

Webster's Seventh New Collegiate Dictionary (7th ed.). Springfield, Mass: G. \& C. Merriam, 1967.

WINER, B. J. Statistical principles in experimental design. (2nd ed.). New York: McGraw-Hill, 1971.

(Received for publication January 12, 1977.) 